\title{
Extracellular Matrix Abnormalities in Polycystic Kidney Disease
}

\author{
Soundarapandian Vijayakumar \\ University of Rochester Medical Center, \\ Rochester, NY, \\ USA
}

\section{Introduction}

Polycystic kidneys diseases (PKD) are a group of monogenic kidney disorders that lead to cyst development in the kidneys. Polycystic kidney diseases are a common indication for renal transplantation and dialysis and a leading cause of end-stage renal disease (ESRD). There are two types of PKD, the autosomal dominant type called ADPKD with an estimated prevalence rate of 1:400-1:1000 worldwide (Torres \& Harris, 2009) and autosomal recessive PKD (ARPKD) with an estimated prevalence rate of 1:10,000-1:20,000. ADPKD is the most common form of PKD, whereas ARPKD is the most lethal form and affects newborns. ADPKD is attributed to several mutations in one or both of the two genes PKD1 and PKD2, whereas ARPKD is attributed to mutations in the PKHD1 gene. The protein products of PKD1 and PKD2 are transmembrane proteins called polycystin 1 and polycystin 2 respectively, whereas the protein product of PKHD1, also a transmembrane protein is termed as fibrocystin. In ADPKD, the cysts arise throughout the nephron segments, whereas in ARPKD, cysts arise from the collecting duct as fusiform dilatations. In addition to kidney cysts, PKD patients generally also exhibit liver disease. Abnormalities in electrolyte secretion (Yamaguchi et al., 1997), EGF and cAMP dependent cell proliferation (Hanaoka and Guggino (2000); Richards et al., 1998), cell-matrix interaction (Ramasubbu et al., 1998; Wilson et al., 1992) and planar cell polarity (Fisher et al., 2006; Patel et al., 2008) have all been attributed to the disease mechanism of PKD. However, the exact cause of cystogenesis is yet unknown. Following Dr. Grantham's seminal work showing abnormal fluid secretion in ADPKD (Grantham, 1993), considerable progress has been done in that area (Magenheimer et al., 2006). Our understanding of the role of cAMP in cystogenesis has led to the development of high potency antagonists to vasopressin V2 receptors as therapeutic agents for ADPKD, which are currently undergoing clinical trials. There has been a great interest in understanding the role of primary cilia in PKD cystogenesis since several of the PKD associated proteins have been reported be localized to primary cilia in addition to other locations in the kidney epithelia (Yoder at al., 2002; Wang et al., 2007). However, the role of abnormal extracellular matrix in cystogenesis has not been pursued rigorously. This review will explore the current and past work that has been undertaken in this area. 


\section{Early observations of ECM abnormalities in PKD}

The first observations of basement membrane abnormalities in PKD were observed as early as 1970 (Darmady et al., 1970). In 1980, Dr. Grantham and colleagues investigated 20 ADPKD cysts from five patients morphologically using electron microscope and observed that the basement membranes of PKD cysts were highly variable in appearance (Cuppage et al., 1980). Some were of reasonably normal thickness, whereas others were thickened or extensively laminated. Also, they observed that nearly every cyst had an abnormal basement membrane. In 1986, Patricia Wilson and her colleagues observed that human PKD epithelial cells in culture exhibited an extremely abnormal basement membrane morphology consisting of some banded collagen and numerous unique blebs or spheroids (Wilson et al., 1986). These blebs stained with ruthenium red, suggesting a proteoglycan component. After performing echocardiographic investigations on 160 ADPKD patients, 130 unaffected family members and 100 control subjects Hossack et al., concluded that cardiovascular abnormalities frequently accompanied PKD and suggested that PKD may be systemic disorder caused by abnormal extracellular matrix (Hossack et al., 1988). Using a murine model of congenital polycystic kidney disease, Ebihara et al., observed that that the components of the peri-cystic basement membrane appeared to diminish with time (Ebihara et al., 1988). Using mRNA measurements, they observed that in normal kidneys, mRNA levels for the B1 and B2 chains of laminin (currently the beta and gamma chains), were maximal at birth, and at 1 week for the alpha $1(\mathrm{IV})$ chain of collagen IV. With all three chains, the levels then rapidly declined. In contrast, mRNA for the collagen alpha 1 (IV) chain in congenital polycystic kidneys was half normal 1 week after birth and then increased. Laminin B1 and B2 chain mRNAs were $80 \%$ of normal at 1 week but were maintained at that level. They concluded that there exists an abnormal regulation of basement membrane gene expression in congenital polycystic kidney disease. In 1992, Yashpal Kanwar and his colleagues observed altered synthesis and intracellular transport of proteoglycans by human ADPKD cyst derived epithelia (Jin et al., 1992). In a Kidney International article in 1993, Jim Calvet critically reviewed the question of whether the extracellular matrix abnormality is a primary defect in PKD (Calvet, 1993). Some early investigations suggested that tubular dilation could result from a loss of basement membrane tensile strength or to increased elasticity and that a tubular basement membrane was a primary defect in PKD. However, when basement membrane elasticity was measured directly by physical viscoelastic tests, it was determined that normal and cystic basement membranes were equally compliant. Jim Calvet also reviewed the results from two PKD model systems namely the $c p k$ and $p c y$ models. Primary epithelial cultures of cpk kidneys showed increased incorporation of 35smethionine into collagen IV (approximately twofold) and into laminin. In human ADPKD kidneys, there is increased collagen IV mRNA level, particularly at end-stage. In the pcy mouse, laminin and collagen IV mRNA levels are somewhat increased in the early stages and more significantly elevated in the latter stages of the disease. Based on these results, it was suggested that a change in basement membrane collagen synthesis may not be a major factor in the initiation of cysts; the change is small and does not occur uniformly in early cyst formation. This review suggested that changes in ECM gene expression are more significant only at end-stage and therefore may be due to a late-stage compensatory response of the kidney to repair its tubular morphology. 


\section{Recent studies}

In 2003, Joly et al., investigated nine ADPKD kidneys retrieved from patients with end-stage renal failure and one ADPKD kidney harvested before the onset of renal failure Joly et al., 2003). Using immunostaining, they showed that Laminin-332 and integrin $\beta 4$ (a ligand of laminin-332) are aberrantly expressed in the pericystic ECM of ADPKD kidneys. Furthermore, using real-time PCR studies performed on the RNA extracted from primary cultures of the cystic epithelia derived from ADPKD kidneys as well as from PKD kidney tissues, they confirmed the abnormal expression of integrin $\beta 4$ and laminin $\gamma 2$ in ADPKD. The same authors presented a more rigorous study on the role of abnormal expression of laminin-332 in ADPKD cystogenesis (Joly et al., 2006). They demonstrated that ADPKD primary cultures synthesized and secreted laminin-332 which was then incorporated into the ECM of cysts that developed in matrigel cultures of these cells. Their studies also showed that addition of various amounts of laminin-332 in the 3D culture system enhanced cyst formation, as assessed by the number of cysts per optic field at day 7 , whereas addition of laminin-332 function blocking antibody (D4B5) drastically reduced the number of cysts formed at day 7 by $73 \pm 9 \%$. Also, they showed that in monolayers, purified laminin-332 induced ERK activation and proliferation of ADPKD cells, and function-blocking antilaminin $\gamma 2$ antibody reduced the sustained ERK activation induced by epidermal growth factor stimulation. Using real time PCR, western blotting and immunostaining, we have demonstrated that laminin-332, particularly laminin $\gamma 2$, is abnormally expressed in the PCK rat model of ARPKD (Vijayakumar et al., 2011). The abnormal expression of laminin-332 is not only observed in the cystic structures, but in the precystic collecting ducts also suggesting a possible role for aberrant laminin-332 expression in PKD cystogenesis.

A definitive role of ECM in PKD cystogenesis was established by Jeff Miner and his colleagues (Shannon et al., 1996). They generated a hypomorphic mutation in laminin $\alpha 5$, a major tubular and glomerular basement membrane component that is important for glomerulogenesis and ureteric bud branching by inserting a PGKneo cassette in an intron of the laminin $\alpha 5$ (Lama5) gene. Lama5neo represents a hypomorphic allele as a result of aberrant splicing. Lama5neo/neo mice exhibited PKD, proteinuria, and death from renal failure by $4 \mathrm{wk}$ of age, whereas the mice that totally lack Lama5 die in utero with multiple developmental defects. At $2 \mathrm{~d}$ of age, Lama5neo/neo mice exhibited mild proteinuria and microscopic cystic transformation. By $2 \mathrm{wk}$, cysts were grossly apparent in cortex and medulla, involving both nephron and collecting duct segments. Tubular basement membranes seemed to form normally, and early cyst basement membranes showed normal ultrastructure but developed marked thickening as cysts enlarged. Overall, Laminin alpha5 protein levels were severely reduced as a result of mRNA frameshift caused by exon skipping. This was accompanied by aberrant accumulation of laminin-332 (laminin-5) in some cysts.

Recently, Ian Drummond and his colleagues have shown that in zebrafish, combined knockdown of the PKD1 paralogs $p k d 1 a$ and $p k d 1 b$ resulted in dorsal axis curvature, hydrocephalus, cartilage and craniofacial defects, and pronephric cyst formation at low frequency (10-15\%) (Mangos et al., 2010). Dorsal axis curvature was identical to the axis defects observed in $p k d 2$ knockdown embryos. Combined $p k d 1 a / b, p k d 2$ knockdown showed that these genes interact in axial morphogenesis. Dorsal axis curvature was linked to notochord collagen overexpression and could be reversed by knockdown of col2a1 mRNA 
or chemical inhibition of collagen crosslinking. $p k d 1 a / b$ - and $p k d 2$-deficient embryos exhibited ectopic, persistent expression of multiple collagen mRNAs, suggesting a loss of negative feedback signaling that normally limits collagen gene expression. Knockdown of $p k d 1 a / b$ also dramatically sensitized embryos to low doses of collagen-crosslinking inhibitors, implicating polycystins directly in the modulation of collagen expression or assembly. Embryos treated with PI3 kinase inhibitors wortmannin or LY-29400 also exhibited dysregulation of col2a1 expression, implicating phosphoinositide 3-kinase (PI3K) in the negative feedback signaling pathway controlling matrix gene expression. They suggested that $p k d 1 a / b$ and $p k d 2$ interact to regulate ECM secretion or assembly, and that altered matrix integrity may be a primary defect underlying ADPKD tissue pathologies.

Patricia Wilson and colleagues have recently implicated the role of focal adhesions in cystogenesis (Israeli et al., 2010). By comparing ARPKD cells, normal age matched human fetal (HFCT) cells and HFCT cells with $85 \%$ fibrocystin-1 silencing, they observed that fibrocystin-1-deficient cells had accelerated attachment and spreading on collagen matrix and decreased motility. Also, the fibrocystin-1-deficient cells were associated with longer paxillin-containing focal adhesions, more complex actin-cytoskeletal rearrangements, and increased levels of total $\beta 1$-integrin, c-Src, and paxillin.

\section{ECM and PKD fibrosis}

One of the features of PKD, particularly ADPKD is the high variability in the age of onset of renal functional decline and the severity of disease progression. This variability has been attributed to mutations in other disease modifier genes (second hit) as well as epigenetic factors. Even if ECM abnormalities fail to be the primary PKD defect, it is almost certain that they play an important role in disease progression by contributing to renal fibrosis. Although there is not much known about the contribution of renal fibrosis in PKD disease progression, a recent review by Jill Norman presents a comprehensive and convincing argument to focus on this area of investigation (Norman, 2011). In this review, it is pointed out that in ADPKD, expansion of cysts and loss of renal function are associated with progressive fibrosis. Similar to the correlation between tubulointerstitial fibrosis and progression of chronic kidney disease (CKD), in ADPKD, fibrosis has been identified as the most significant manifestation associated with an increased rate of progression to ESRD. It is important to note that although fibrosis in CKD has been studied extensively, little is known about the mechanisms underlying PKD fibrosis. In this review, she concludes that the current data indicate that fibrosis associated with ADPKD shares at least some of the "classical" features of fibrosis in CKD (increased interstitial collagens, changes in MMPs, overexpression of TIMP-1, over-expression of PAI-1 and increased TGF $\beta$ ) and points out that there are also some unique and stage-specific features. Based on the review of current literature, she suggests that epithelial changes appear to precede and to cause changes in the interstitium. It is also proposed that the development of fibrosis in ADPKD is a biphasic process with alterations in the cystic epithelia followed by changes in the interstitial fibroblasts and that reciprocal interaction between these cell types precipitate a progressive accumulation of ECM in the interstitial compartment. Since fibrosis is a major component of ADPKD it follows that preventing or slowing fibrosis should retard disease progression with obvious therapeutic benefits. 


\section{Conclusion}

New studies cited in this review bring back the focus on the role ECM in PKD cystogenesis and fibrosis. Current results such as the study showing laminin alpha 5 hypomorphic mutation leads to cystic kidneys in mice, abnormal expression of laminin-332 in cysts and precystic tubules of PCK rat kidneys and aberrant expression of laminin-332 and integrin beta 4 in human ADPKD tissues, all point to the possible role of abnormal ECM in PKD cystogenesis. However it is possible that the mechanism that causes cyst formation is something other than the primary ECM defect and that the abnormal ECM observed in PKD aids in the progression of the disease by contributing to the mechanisms of fibrosis.

\section{Acknowledgment}

I thank the Department of Pediatrics, University of Rochester Medical Center for financial support and Prof. Vicente Torres, M.D., Ph.D. (Mayo Clinic) for his guidance and support.

\section{References}

Calvet JP. (1993) Polycystic kidney disease: primary extracellular matrix abnormality or defective cellular differentiation? Kidney Int. 43:101-108.

Cuppage FE, Huseman RA, Chapman A, Grantham JJ. (1980) Ultrastructure and function of cysts from human adult polycystic kidneys. Kidney Int. 17(3):372-81

Darmady EM, Offer J, Woodhouse MA. (1970) Toxic metabolic defect in polycystic disease of kidney: Evidence from microscopic studies. Lancet 1:547-550.

Ebihara I, Killen PD, Laurie GW, Huang T, Yamada Y, Martin GR, Brown KS. (1988) Altered mRNA expression of basement membrane components in a murine model of polycystic kidney disease. Lab Invest. 58:262-269

Fischer E, Legue E, Doyen A, Nato F, Nicolas JF, Torres V, Yaniv M, Pontoglio M. (2006) Defective planar cell polarity in polycystic kidney disease. Nat Genet. 38(1):21-3.

Grantham JJ. (1993) Homer Smith Award. Fluid secretion, cellular proliferation, and the pathogenesis of renal epithelial cysts. J Am Soc Nephrol. 3:1841-57.

Hanaoka K, and Guggino WB. (2000) cAMP regulates cell proliferation and cyst formation in autosomal polycystic kidney disease cells. J.Am. Soc.Nephrol.11:1179-1187.

Hossack KF, Leddy CL, Johnson AM, Schrier RW, Gabow PA. (1988) Echocardiographic findings in autosomal dominant polycystic kidney disease. N Engl J Med.319:907-12

Israeli S, Amsler K, Zheleznova N, Wilson PD. (2010) Abnormalities in focal adhesion complex formation, regulation, and function in human autosomal recessive polycystic kidney disease epithelial cells. Am J Physiol Cell Physiol. 298(4):C831-846

Jin H, Carone FA, Nakamura S, Liu ZZ, Kanwar YS. (1992) Altered synthesis and intracellular transport of proteoglycans by cyst-derived cells from human polycystic kidneys. J Am Soc Nephrol. 2:1726-33.

Joly D, Morel V, Hummel A, Ruello A, Nusbaum P, Patey N, Noël LH, Rousselle P, Knebelmann B. Beta4 integrin and laminin 5 are aberrantly expressed in polycystic kidney disease: role in increased cell adhesion and migration. Am J Pathol. 163:1791-800 (2003).

Joly D, Berissi S, Bertrand A, Strehl L, Patey N, Knebelmann B. (2006) Laminin 5 regulates polycystic kidney cell proliferation and cyst formation. J Biol Chem. 281:29181-29189. 
Magenheimer BS, St John PL, Isom KS, Abrahamson DR, De Lisle RC, Wallace DP, Maser RL, Grantham JJ, Calvet JP. (2006) Early embryonic renal tubules of wild-type and polycystic kidney disease kidneys respond to cAMP stimulation with cystic fibrosis transmembrane conductance regulator $/ \mathrm{Na}(+), \mathrm{K}(+), 2 \mathrm{Cl}(-)$ Co-transporterdependent cystic dilation. J Am Soc Nephrol. 17:3424-37.

Mangos S, Lam PY, Zhao A, Liu Y, Mudumana S, Vasilyev A, Liu A, Drummond IA. (2010) The ADPKD genes $p k d 1 a / b$ and $p k d 2$ regulate extracellular matrix formation. Dis Model Mech.3(5-6):354-65.

Norman J. (2011) Fibrosis and progression of autosomal dominant polycystic kidney disease (ADPKD). Biochim Biophys Acta. 1812:1327-1336.

Patel V, Li L, Cobo-Stark P, Shao X, Somlo S, Lin F, Igarashi P. (2008) Acute kidney injury and aberrant planar cell polarity induce cyst formation in mice lacking renal cilia. Hum Mol Genet. 17:1578-90.

Ramasubbu K, Gretz N, Bachmann S. (1998) Increased epithelial cell proliferation and abnormal extracellular matrix in rat polycystic kidney disease. J Am Soc Nephrol. 9:937-45

Richards WG, Sweeney WE, Yoder BK, Wilkinson JE, Woychik RP and Avner ED. (1998) Epidermal growth factor receptor activity mediates renal cyst formation in polycystic kidney disease. J. Clin. Invest. 101:935-939

Shannon BM, Patton BL, Harvey, SJ and Miner JH. (2006) A Hypomorphic Mutation in the Mouse Laminin $\alpha 5$ Gene Causes Polycystic Kidney Disease. J Am Soc Nephrol 17: 1913-1922.

Torres VE and Harris PC. (2009) Autosomal dominant polycystic kidney disease: the last 3 years. Kidney Int.76(2):149-68.

Vijayakumar S, Parkhi K, and Stolar J. Abnormal expression and assembly of laminin-332 and laminin-511 in ARPKD. JASN 22: Kidney week 2011 abstracts, 576A-577A, (2011)

Wang S, Zhang J, Nauli SM, Li X, Starremans PG, Luo Y, Roberts KA, Zhou J. (2007) Fibrocystin/polyductin, found in the same protein complex with polycystin-2, regulates calcium responses in kidney epithelia. Mol Cell Biol. 27(8):3241-52.

Wilson PD, Schrier RW, Breckon RD, Gabow PA. (1986) A new method for studying human polycystic kidney disease epithelia in culture. Kidney Int. 30(3):371-8.

Wilson PD, Hreniuk D, Gabow PA. (1992) Abnormal extracellular matrix and excessive growth of human adult polycystic kidney disease epithelia. J Cell Physiol. 150:360-9.

Yamaguchi T, Nagao S, Kasahara M, Takahashi H, Grantham JJ. (1997) Renal accumulation and excretion of cyclic adenosine monophosphate in a murine model of slowly progressive polycystic kidney disease. Am J Kidney Dis. 30(5):703-709

Yoder BK, Hou X, Guay-Woodford LM. (2002) The polycystic kidney disease proteins, polycystin-1, polycystin-2, polaris, and cystin, are co-localized in renal cilia. J Am Soc Nephrol. 13(10):2508-2516 


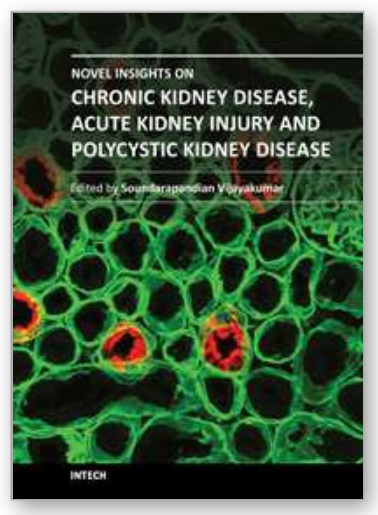

\section{Novel Insights on Chronic Kidney Disease, Acute Kidney Injury and Polycystic Kidney Disease}

Edited by Dr. Soundarapandian Vijayakumar

ISBN 978-953-51-0234-2

Hard cover, 134 pages

Publisher InTech

Published online 07, March, 2012

Published in print edition March, 2012

This book offers novel insights on topics such as congenital obstructive nephropathy, cerebral-renal salt wasting, and the role of hemoglobin variability in clinical outcomes of CKD which are not very often discussed in the literature. With comprehensive and insightful reviews by eminent clinicians and scientists in the field, this book is a valuable tool for nephrologists.

\section{How to reference}

In order to correctly reference this scholarly work, feel free to copy and paste the following:

Soundarapandian Vijayakumar (2012). Extracellular Matrix Abnormalities in Polycystic Kidney Disease, Novel Insights on Chronic Kidney Disease, Acute Kidney Injury and Polycystic Kidney Disease, Dr. Soundarapandian Vijayakumar (Ed.), ISBN: 978-953-51-0234-2, InTech, Available from: http://www.intechopen.com/books/novelinsights-on-chronic-kidney-disease-acute-kidney-injury-and-polycystic-kidney-disease/extracellular-matrixabnormalities-in-polycystic-kidney-disease

\section{INTECH}

open science | open minds

\section{InTech Europe}

University Campus STeP Ri

Slavka Krautzeka 83/A

51000 Rijeka, Croatia

Phone: +385 (51) 770447

Fax: +385 (51) 686166

www.intechopen.com

\section{InTech China}

Unit 405, Office Block, Hotel Equatorial Shanghai

No.65, Yan An Road (West), Shanghai, 200040, China

中国上海市延安西路65号上海国际贵都大饭店办公楼 405 单元

Phone: +86-21-62489820

Fax: $+86-21-62489821$ 
(C) 2012 The Author(s). Licensee IntechOpen. This is an open access article distributed under the terms of the Creative Commons Attribution 3.0 License, which permits unrestricted use, distribution, and reproduction in any medium, provided the original work is properly cited. 